\title{
Cold Storage Dengan Sistem Kompresor Backup Untuk Penyimpanan Vaksin
}

\section{Cold Storage with Backup Compressor System for Vaccine Storage}

\author{
Abdul Azis Fitriaji ${ }^{1}$, Alvian Ari Anoor ${ }^{2}$, Muhammad Ilham Alhabsyie ${ }^{3}$, Awang Surya ${ }^{4 *}$ \\ 1,2,3,4* Program Studi Teknik Mesin, Sekolah Tinggi Teknologi Muhammadiyah Cileungsi \\ $1,2,3,4^{*} \mathrm{Jl}$. Anggrek No 25, Perum PTSC, Cileungsi, Bogor, Jawa Barat-Indonesia \\ *Koresponden Email: awang.surya.68@gmail.com
}

\begin{abstract}
Abstrak. Sehubungan dengan terjadinya pandemi covid -19 , vaksin menjadi produk yang sangat penting. Implementasi vaksinasi memerlukan perencanaan yang amat rinci, mobilisasi sumber daya secara optimal. Penyimpanan vaksin merupakan hal yang vital dalam program vaksinasi. Penyimpanan yang buruk akan berakibat gagalnya program vaksinasi. Penyimpanan vaksin memerlukan suhu antara 2-8 derajat Celcius, agar supaya komponen dalam vaksin yang bersifat bioaktif tidak mengalami kerusakan karena suhu yang tinggi atau suhu yang terlalu rendah, sehingga dengan suhu penyimpanan yang tepat, potensi proteksi vaksin akan tetap terjaga. Untuk itu vaksin harus disimpan di dalam ruangan yang dapat menjaga kestabilan suhunya agar tidak mengalami kerusakan, yaitu disimpan di cold storage. Umumnya cold storage menggunakan satu mesin kompresor. Jika terjadi sesuatu pada kompresor maka akan berakibat kerusakan pada vaksin. Sebagai upaya menjamin keamanan maka perusahaan PT. XYZ berinovasi untuk mendesain cold storage dengan 2 mesin. Apabila salah satu mesin kompresor mengalami gagal running maka kompresor yang lain akan secara otomatis running untuk mem-back up mesin yang mengalami kerusakan. Tujuan dari penelitian ini adalah untuk mengetahui apakah cold storage dengan sistem back up sebagai solusi penyimpan vaksin covid-19 dapat berfungsi dengan baik. Metode yang digunakan dalam menelitian ini adalah metode deskriptif yaitu penelitian yang berusaha menggambarkan objek penelitian secara objektif. Hasil penelitian dapat diketahui bahwa cold storage berfungsi dengan baik.
\end{abstract}

Kata kunci: Sistem pendingin, sistem compressor back up, cold storage, vaksin

Abstract. Due to the COVID-19 pandemic, vaccines have become a very important product. Implementation of vaccination requires very detailed planning, optimal mobilization of resources. Vaccine storage is vital in any vaccination program. Poor storage will result in the failure of the vaccination program. Vaccine storage requires a temperature between 2-8 degrees Celsius, so that the components in the vaccine that are bioactive are not damaged due to high temperatures or too low temperatures, so that with the right storage temperature, the potential for vaccine protection will be maintained. For this reason, vaccines must be stored in a room that can maintain a stable temperature so as not to be damaged, which is stored in cold storage. Generally cold storage uses one compressor machine. If something happens to the compressor it will damage the vaccine. As an effort to ensure security, the company PT. XYZ innovates to design cold storage with 2 machines. If one of the compressor machines fails to run, the other compressors will automatically run to back up the damaged machine. The purpose of this study was to find out whether cold storage with a back-up system as a Covid-19 vaccine storage solution can function properly. The method used in this research is descriptive method. The results of the study can be seen that cold storage functions well.

Keywords: cooling system, compressor back up system, cold storage, vaccine

\section{PENDAHULUAN}

Teknologi di bidang refrigerasi mengalami kemajuan yang pesat seiring berkembangnya zaman.

Teknik refrigerasi digunakan dengan tujuan untuk mempertahankan temperatur suatu area tertentu

JTTM: Jurnal Terapan Teknik Mesin is licensed under a Creative Commons AttributionNonCommercial 4.0 International License. 
agar tetap lebih rendah dari temperatur sekelilingnya[1]. Dengan pengaturan udara pada suatu ruangan yang mengatur kondisi kelembaban, pemanasan dan pendinginan, dimaksudkan untuk memberikan suhu yang stabil dan dapat dipertahankan keadaan untuk kebutuhan suatu produk. Produk yang disimpan dengan sistem refrigerasi akan terjaga kualitas dan kesegarannya serta mampu bertahan lebih lama selama penyimpanan.

Prinsip kerja dari sistem refrigerasi yaitu menurunkan suhu suaru ruangan, hingga mencapai sekitar $0^{\circ} \mathrm{C}$. Pada suhu rendah aktifitas mikroba, enzim, maupun reaksi kimia dapat ditekan sehingga proses pembusukan dapat diperlambat. Pembekuan maupun pendinginan bertujuan untuk menghambat kegiatan mikro organisme dan proses kimia serta fisik lainnya[2]

Tujuan dari sistem refrigerasi adalah mempertahankan area yang didinginkan pada temperatur di bawah temperatur sekelilingnya. Salah satu produk yang penyimpanannya memerlukan sistem refigerasi adalah vaksin[3]. Vaksin merupakan agen biologis yang memiliki respons imun terhadap antigen spesifik yang berasal dari patogen penyebab penyakit menular[4]. Sejak ditemukannya vaksin dan teknik pembuatan vaksin yang semakin berkembang pesat hingga saat ini, ada satu hal yang mutlak tentang penyimpanan vaksin, yaitu rantai dingin atau cold chain. Penyimpanan vaksin memerlukan suhu antara 2-8 derajat Celsius, agar supaya komponen dalam vaksin yang bersifat bioaktif tidak mengalami kerusakan karena suhu yang tinggi atau suhu yang terlalu rendah, sehingga dengan suhu penyimpanan yang tepat, potensi proteksi vaksin akan tetap terjaga[5].

Simulasi TEWI (total equivalent warming impact) yang mengutamakan dampak lingkungan langsung dan tidak langsung pada pendinginan. Dari analisis ini, disimpulkan bahwa penyimpanan dingin vaksin Oxford-AstraZeneca, Janssen COVID-19, dan CoronaVac menghasilkan dampak lingkungan 35 kali lebih kecil daripada vaksin Pfizer[6].

Penyimpanan dan transportasi vaksin harus memenuhi syarat rantai dingin vaksin yang baik untuk mempertahankan kualitas vaksin. Kualitas vaksin yang rendah menyebabkan vaksin tidak poten sehingga tidak bisa memberikan perlindungan[7]. Untuk itu vaksin harus disimpan di dalam ruangan yang dapat menjaga kestabilan suhunya agar tidak mengalami kerusakan, yaitu disimpan di cold storage. Cold storage adalah peralatan yang digunakan untuk menjaga kualitas produk pada suhu tertentu. Peralatan ini sangat vital dalam rantai industri makanan, minuman, obat-obatan, dan lain-lain yang melibatkan faktor suhu rendah dalam menjaga produknya[8].

Sehubungan dengan terjadinya pandemi covid-19, vaksin menjadi produk yang sangat penting. Vaksinansi adalah kegiatan yang penting untuk menanggulangi pandemi. Implementasinya memerlukan perencanaan yang amat rinci, mobilisasai sumber daya secara optimal[9]. Penyimpanan vaksin merupakan hal yang vital dalam program vaksinasi. Penyimpanan yang buruk akan berakibat gagalnya program vaksinasi.

Pada umumnya cold storage menggunakan satu mesin kompresor. Jika terjadi kerusakan pada kompresor maka akan berakibat kerusakan pada vaksin. Sebagai upaya menjamin keamanan maka 
perusahaan PT. XYZ berinovasi untuk mendesain cold storage dengan 2 mesin kompresor. Masingmasing kompresor bekerja dalam waktu 12 jam per hari secara bergantian. Apabila salah satu mesin kompresor mengalami gagal running maka kompresor yang lain akan secara otomatis running untuk mem-back up mesin yang mengalami kerusakan. Tujuan dari penelitian ini adalah untuk mengetahui apakah cold storage dengan sistem back up sebagai solusi penyimpan vaksin covid-19 dapat berfungsi dengan baik.

\section{METODE.}

Penelitian ini dilakukan dengan metode deskriptif, yaitu metode penelitian yang berusaha menggambarkan objek atau subyek yang diteliti secara objektif, dan bertujuan menggambarkan fakta secara sistematis dan karakteristik objek serta frekuensi yang diteliti secara tepat. Pada umumnya, temuan dari penelitian deskriptif adalah dalam, luas dan terperinci[10].

Pengumpulan data dilakukan dengan observasi yaitu salah satu metode pengumpulan data dengan cara mengamati atau meninjau secara cermat dan langsung di lokasi penelitian untuk mengetahui kondisi yang terjadi atau membuktikan kebenaran dari sebuah desain penelitian yang sedang dilakukan[11].

Penelitian dilakukan terhadap cold storage yang telah diinstalasi. Dalam hal ini adalah cold storage dengan sistem kompresor back up yang dirancang dengan penambahan kompresor dari satu unit menjadi dua unit kompresor dan perubahan pada rangkaian panel listrik[12]. Lokasi cold storage yang diobservasi adalah produk yang dirancang bangun oleh PT. XYZ.

Secara sederhana penelitian yang dilakukan secara bertahap dengan urutan seperti flow cart yang terlihat pada gambar 1 .

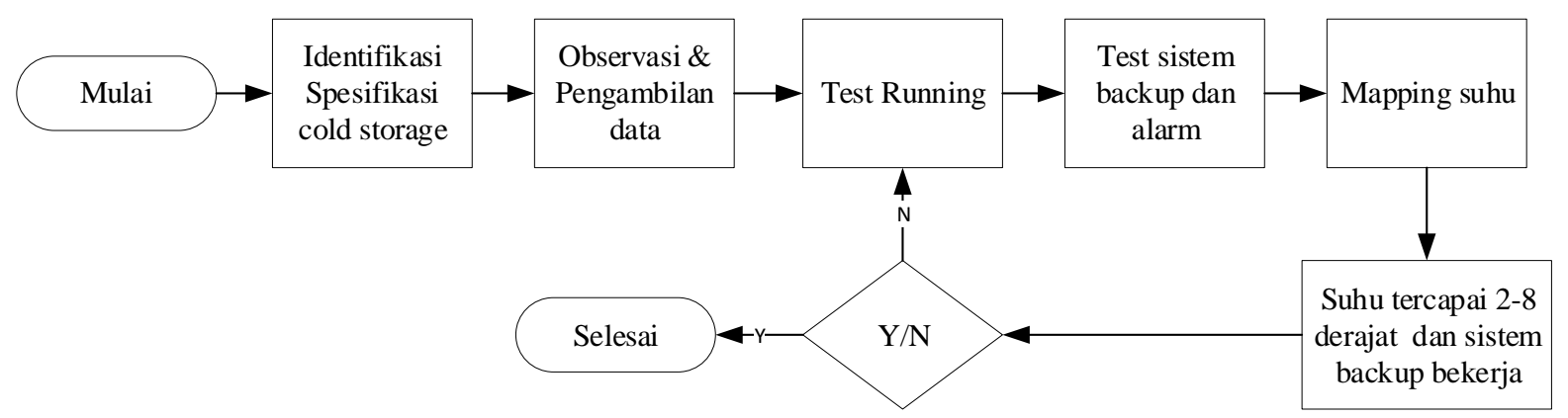

Gambar 1. Diagram alir metode penelitian

\section{HASIL DAN PEMBAHASAN}

Cold storage merupakan suatu mesin pendingin yang menampung benda-benda yang akan mengalami proses pendinginan. Unit cold storage biasa digunakan dalam kehidupan seharihari untuk untuk mendinginkan atau mengawetkan berbagai macam produk seperti daging, minuman, sayuran buah-buahan dan macam lainya[13]. Secara sederhana komponenkomponen pendukung dari cold storage adalah seperti pada gambar 2. 


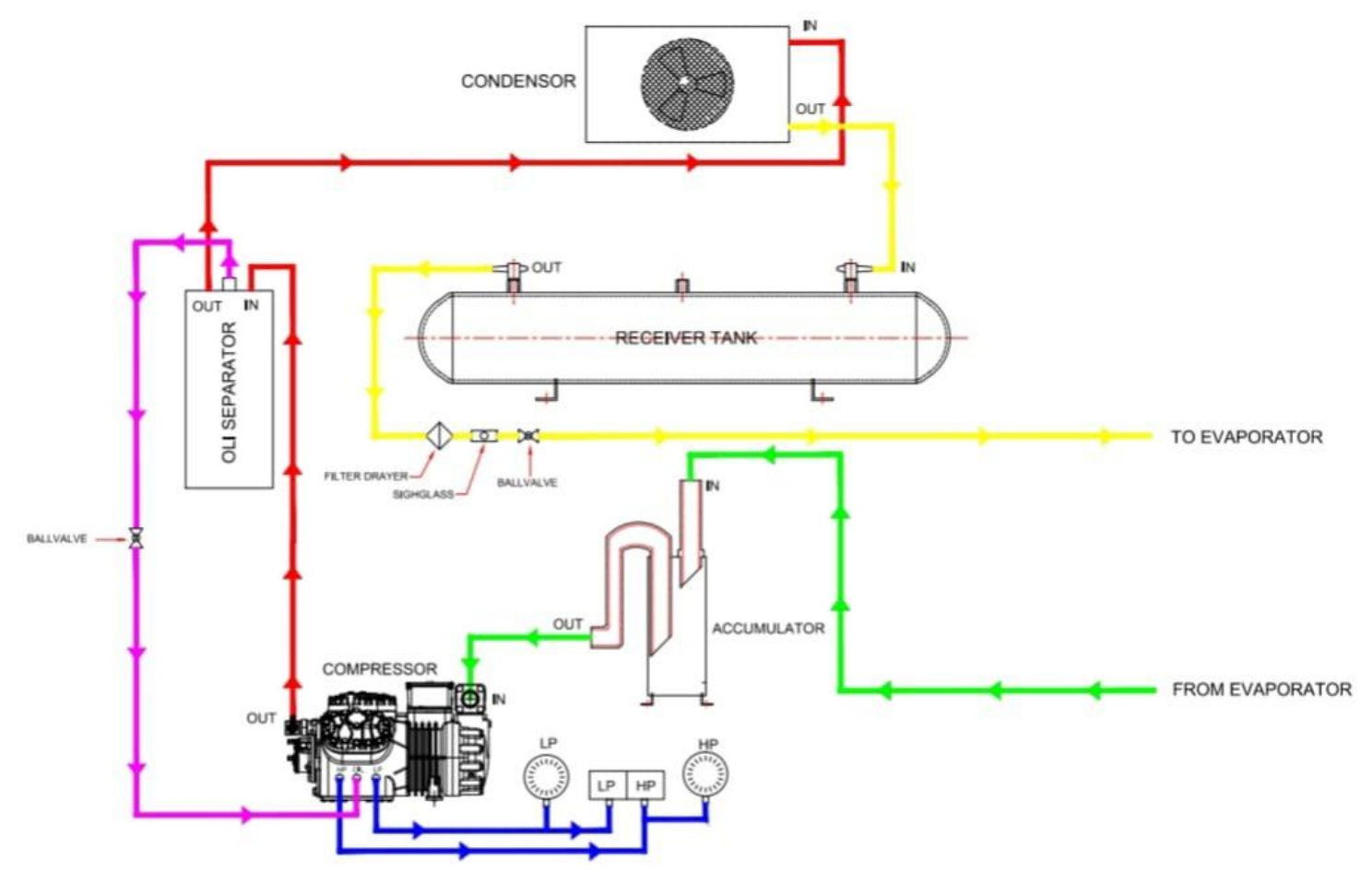

Gambar 2. Schematic system cold storage

Tampilan luar dan bagian dalam dari cold storage yang ada di PT. XYZ adalah seperti terlihat pada gambar 3 dan 4 .

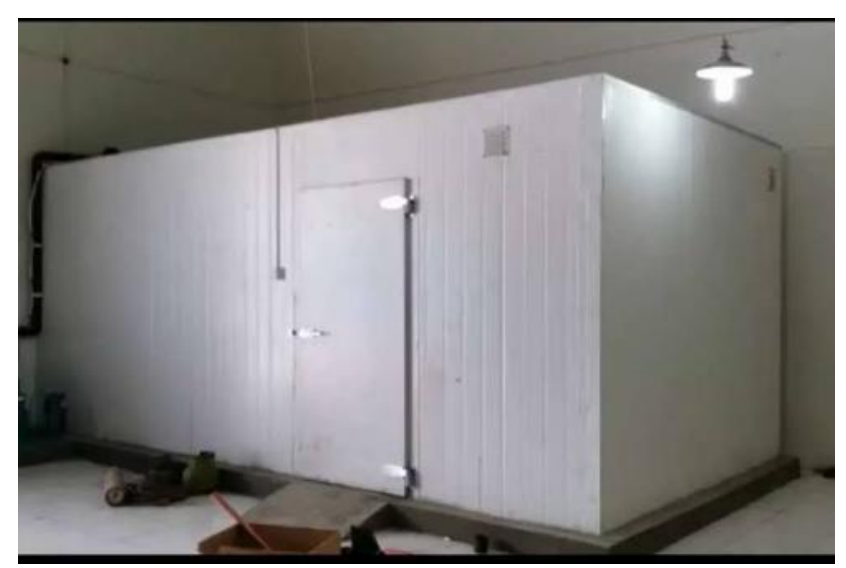

Gambar 3. Tampak luar cold storage

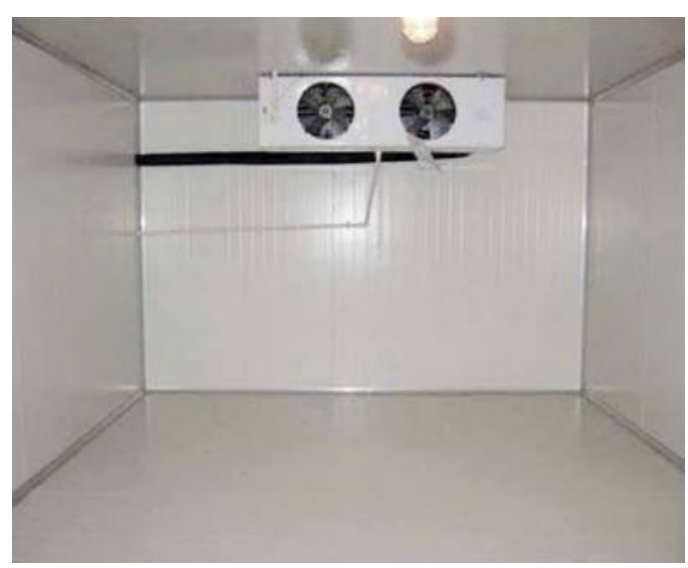

Gambar 4. Bagian dalam cold storage

Komponen-komponen yang ada dalam sistem cold storage adalah sebagai berikut:

a. Condensing unit yang terdiri dari chasis, compresor dan condensor

b. Indoor unit yang terdiri dari evaporator dan katup ekspansi

c. Aksesoris pendukung terdiri dari filter dryer, panel control, solenoid valve, hand valve \& pressure switch. 


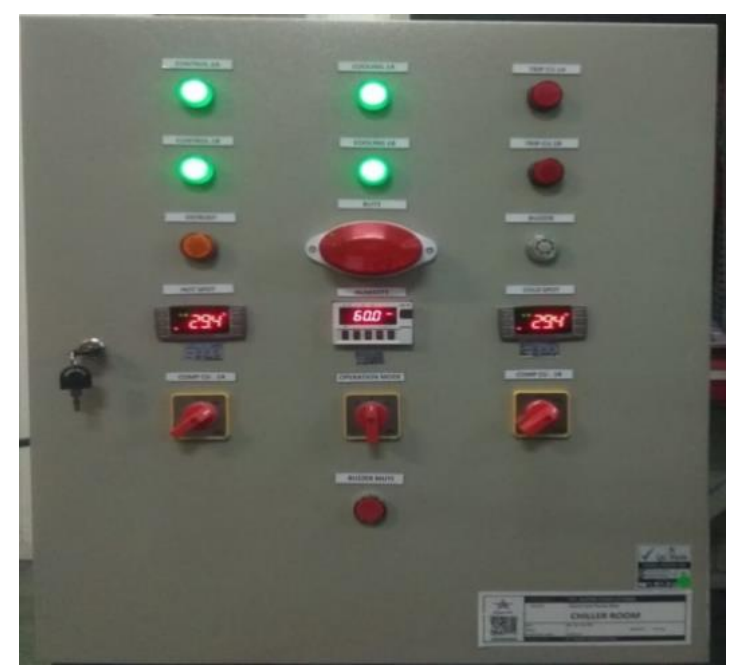

Gambar 5. Electrical panel control.

Dari observasi di lapangan diketahui spesifikasi komponen cold storage yang digunakan adalah seperti terlihat pada tabel 1 .

Tabel 1. Spesifikasi komponen cold storage.

\begin{tabular}{llll}
\hline No & \multicolumn{1}{c}{ Komponen } & \multicolumn{1}{c}{ Type } & \multicolumn{1}{c}{ Keterangan } \\
\hline 1 & Sandwich panel & Polyurethane & 13 lembar \\
2 & Compressor & Bitzer 2ces-4y & 2 unit \\
3 & Condensor & Guntner G.060 & 2 unit \\
4 & Evaporator & Guntner RX 040.1/2-70.A-1820879M & 1 unit \\
5 & Pipa tembaga & ASTM B819 & discharge 3 batang \\
& & discharge 3/8, suction 3/4 & suction 3 batang \\
6 & Panel control & Single panel control & Size 20x70x60 \\
7 & Controlling and & Emerson, XWEB500 EVO & 1 unit \\
& monitoring web server & & 5 can \\
8 & Freon & R404 & \\
\hline
\end{tabular}

Dari observasi yang telah dilakukan diketahui ada beberapa proses yang dilakukan untuk memastikan cold storage bekerja sesuai rencana yaitu running test, back up test, dan mapping suhu. Running test adalah langkah pengujian pada sistem cold storage setelah proses instalasi pengerjaan cold storage dari mulai pemasangan panel sandwich, jalur pipa, condensing unit dan semuanya telah selesai. Sebelum running test dilaksanakan jalur pipa harus sudah divakum. Proses vakum adalah proses pembuangan udara dalam pipa sehingga pipa benarbenar kosong atau hampa udara. Proses running test bertujuan untuk mengetahui apakah terdapat kebocoran pada pengelasan meliputi compressor, condenser, dan evaporator dan untuk memastikan apakah semua sistem bekerja dengan baik. 
Dari hasil running test didapatkan cold storage berfungsi dengan baik, jika terjadi kebocoran pada sistem pendingin, sistem kelistrikan, sistem pemipaan, bisa segera dilakukan perbaikan.

Jika pemasangan pipa tidak sesuai dengan drawing maupun standar material yang dipergunakan akan berdampak terhadap laju aliran pendingin cold storage, dan dampak yang lain adalah kebocoran sistem pendingin. Penggunaan cold storage juga secara signifikan mengurangi ukuran unit pendingin, yang berkontribusi pada pengurangan investasi awal[14].

Saat running test, dilakukan pengisian freon dan running mesin secara bertahap dengan melihat tekanan pada pressure gauge dan pengukuran arus listrik. Hal ini dimaksudkan agar tidak berlebihan ataupun kekurangan dalam pengisian freon, sehingga mesin dapat bekerja dengan baik. Pada running test ada beberapa bagian yang harus di-setting. Salah satunya di bagian mesin ada sebuah komponen pressure gauge H/L PRESS yang harus di-setting dengan memutar bagian atas $H / L$ PRESS. H/L PRESS memiliki fungsi sebagai pengaman dengan sistem kerja akan memutus control jaringan listrik apabila tekanan terlalu tinggi atau terlalu rendah dari standar. Sedangkan pada panel kontrol ada perangkat digital yang harus di-setting meliputi pengaturan suhu, defrost dan sistem kerja mesin.

Temuan penelitian ini juga mengungkapkan bahwa 35 (58,3\%) memiliki praktik manajemen sistem pendingin vaksin yang tepat dan $25(41,7 \%)$ lainnya memiliki praktik yang tidak tepat. Regresi logistik menunjukkan kepada kita kesenjangan pengetahuan dan profesi secara signifikan terkait dengan praktik manajemen rantai dingin vaksin pada $\mathrm{P}<0,05[15]$.

Vaksin yang disimpan adalah jenis vaksin untuk virus corona dengan merk sinovac yang memerlukan suhu penyimpanan sekitar $2-8^{\circ}$ Celcius. Data settingan pada unit cold storage terlihat pada tabel 2 .

Tabel 2. Setting pada unit cold storage dan panel control

\begin{tabular}{lll}
\hline \multicolumn{1}{c}{ Mesin } & \multicolumn{1}{c}{ Setting } & \multicolumn{1}{c}{ Keterangan } \\
\hline Kompresor A & Jam kerja & 12 jam siang \\
$4 \mathrm{pk}$ & Tekanan low & $40-45 \mathrm{psi}$ \\
& Tekanan high & $250-270 \mathrm{psi}$ \\
& Diferensial press & $15 \mathrm{psi}$ \\
& Temperatur & $2-8^{\circ} \mathrm{C}$ \\
& Arus & $6-7 \mathrm{~A}$ \\
& Durasi defrost & 30 menit \\
& Jangka waktu defrost & 6 jam \\
\hline
\end{tabular}




\begin{tabular}{lll}
\hline Kompresor B & Jam kerja & 12 jam malam \\
$4 \mathrm{pk}$ & Tekanan low & $40-45 \mathrm{psi}$ \\
& Tekanan high & $250-270 \mathrm{psi}$ \\
& Diferensial press & $15 \mathrm{psi}$ \\
& Temperatur & $2-8^{\mathrm{O}} \mathrm{C}$ \\
& Arus & $6-7 \mathrm{~A}$ \\
& Durasi defrost & $30 \mathrm{menit}$ \\
& Jangka waktu defrost & 6 jam \\
\hline
\end{tabular}

Sistem kerja kompresor pada cold storage dengan dua compressor adalah secara bergantian. Masing-masing kompresor bekerja 12 jam siang dan 12 jam malam. Hal ini dimaksudkan agar mesin mendapatkan jeda waktu untuk beristirahat dan mendinginkan mesin. Sistem kerja perggantian kompresor sepenuhnya dikendalikan pada electrical panel box.

Test back up adalah dilakukan dengan cara mencoba mengetripkan overloud kompresor A pada panel control sehingga mesin mati. Pada saat itu mesin kompresor B otomatis hidup mem-backup kompresor A. Sebagai rangkaian back up test adalah tes alarm yaitu pengujian dengan cara sensor dipanaskan melebihi $8^{\circ} \mathrm{C}$ dan sensor didinginkan melebihi $2^{\circ} \mathrm{C}$. Pada kondisi ini pun sistem mengirim sinyal alarm sehingga teknisi dapat mengetahui dan segera menangani masalah yang terjadi pada kompresor yang mati. Alarm berupa suara sirine yang keras dan dengan controlling \& monitoring web server sistem dapat mengirim sinyal sms dan email ke handphone. Dari back up test yang telah dilakukan didapatkan bahwa sistem telah bekerja dengan baik.

Mapping suhu adalah proses pengambilan data temperatur ruangan dengan menggunakan alat termometer khusus yang diletakan pada titik-titik tertentu dalam ruangan selama satu minggu dalam keadaan sistem cold storage bekerja.[16] Tindakan ini bertujuan untuk mendapatkan data suhu ruangan. Mapping suhu dilakukan oleh pihak PT. XYZ. Selama proses ini ruangan tidak boleh dibuka dan listrik tidak boleh mati maka genset pun harus telah siap jika listrik PLN tiba-tiba mati.

Proses mapping suhu untuk mendapatkan data di mana titik-titik tertentu dalam ruangan terdapat selisih perbedaan temperatur, yang disebut hotspot dan cool spot, sehingga kita dapat memposisikan sensor panel control di posisi yang tepat. 


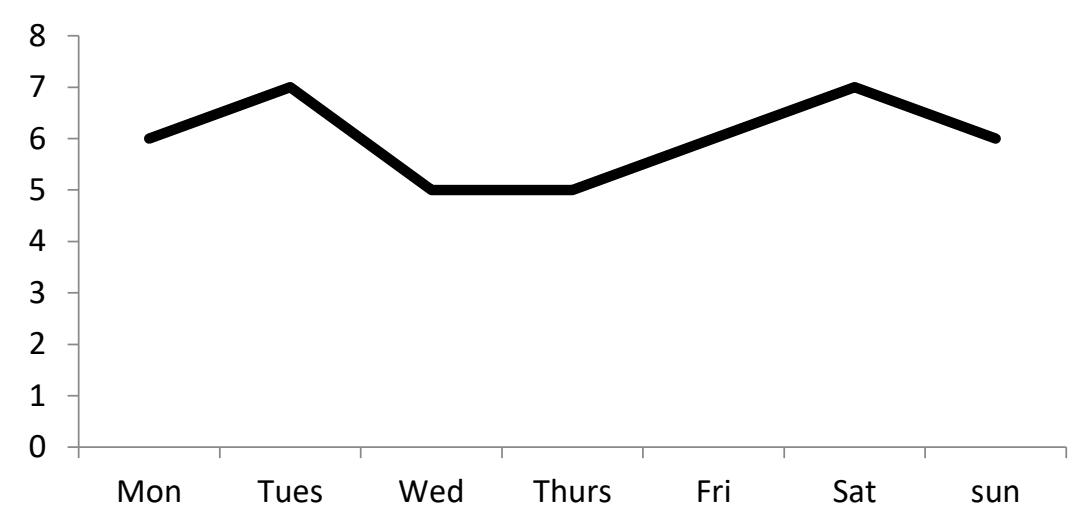

Gambar 6. Grafik temperatur rata-rata.

Tes ini menentukan kelayakan untuk penyimpanan vaksin. Hasil mapping suhu dalam waktu 1 minggu pada tgl 7-13 Juni 2021 terlihat pada gambar 6.

Dari pengujian mapping suhu yang telah dilakukan dapat dipastikan sistem cold storage telah bekerja dengan baik. Hal ini terlihat dari suhu rata-rata selama satu minggu tidak melebihi $8^{\circ}$ Celcius. Dapat diartikan cold storage yang ada bisa dipergunakan untuk menyimpan vaksin Sinovac.

\section{SIMPULAN}

Dari hasil penelitian dapat kita ketahui bahwa cold storage berfungsi dengan baik. Sistem back up bekerja dengan baik. Ketika salah satu kompresor mati, kompresor kedua secara otomatis hidup. Sistem alarm juga berfungsi dengan mengeluarkan bunyi keras, serta terjadi pengiriman pesan sms kepada nomor HP petugas. Dari hasil mapping suhu diketahui bahwa cold storage layak digunakan untuk menyimpan vaksin Sinovac, karena suhu tidak melebihi $8^{\circ}$ Celcius.

\section{REFERENSI}

[1] A. Pujianto, M. Z. Latif A., and W. Septiandi, "Analisa Kinerja Sistem Refrigerasi Berdasarkan Beban Pendinginan Ruang Pembekuan Pada Kapal Penampung Ikan,” J. Kelaut. Nas., 2020, doi: 10.15578/jkn.v15i1.7856.

[2] M. Mardiyono and H. Fadillah, "Perhitungan Beban Refrigerasi Terhadap Hasil Tangkapan Pada Km. Harapan Sri Jaya Juwana, Pati, Jawa Tengah,” J. Rekayasa Mesin, 2020, doi: 10.32497/jrm.v15i3.1779.

[3] K. A. and M. M., "Assessment of vaccine cold chain management status at service delivery health facilities in dawro zone, South West Ethiopia," Pharmacoepidemiol. Drug Saf., vol. 25, no. Supplement 3, 2016. 
[4] I. P. Sari and S. Sriwidodo, "Perkembangan Teknologi Terkini dalam Mempercepat Produksi Vaksin COVID-19," Maj. Farmasetika, 2020, doi: 10.24198/mfarmasetika.v5i5.28082.

[5] R. Warihwati, "MENJAMIN KUALITAS VAKSIN DENGAN MANAJEMEN RANTAI DINGIN," J. Manaj. Ind. DAN LOGISTIK, 2017, doi: 10.30988/jmil.v1i1.7.

[6] A. F. Santos, P. D. Gaspar, and H. J. L. de Souza, "Refrigeration of COVID-19 vaccines: Ideal storage characteristics, energy efficiency and environmental impacts of various vaccine options," Energies, vol. 14, no. 7, 2021, doi: 10.3390/en14071849.

[7] Faradiba Hikamarida, "Keeratan Penyimpanan dan Pencatatan dengan Kualitas Rantai Dingin Vaksin DPT di Puskesmas," J. Berk. Epidemiol. Vol. 2 NO. 3 Sept. 2014 380$391,2014$.

[8] A. Najmurrokhman, "Cold Storage Menggunakan Mikrokontroler," J. Teknol., 2018.

[9] T. Y. Aditama, "Perkembangan Vaksin COVID-19," eJournal Kedokt. Indones., 2021, doi: 10.23886/ejki.8.12870.

[10] C. M. Zellatifanny and B. Mudjiyanto, “TIPE PENELITIAN DESKRIPSI DALAM ILMU KOMUNIKASI," Diakom J. Media dan Komun., 2018, doi: 10.17933/diakom.v1i2.20.

[11] Zakky, "Pengertian Observasi Menurut Para Ahli dan Secara Umum [Lengkap]," Www.Zonareferensi.Com, 2020.

[12] S. D. E. Gestaci and C. Gestaci, “Ar Er Er Er Er,” no. 2, pp. 1-7, 2010.

[13] D. M. Nasution, "Perencanaan Instalasi Pengujian Cold Storage Kapasitas Refrigerasi 765 Watt Skala Laboratorium,” P4M STTH. 2011.

[14] C. Zhang, L. Yang, W. Lin, J. Wei, J. Chen, and Z. Ma, "Experimental investigation and life-cycle cost analysis of a cold storage enhanced vacuum cooling system using ice slurry," Sustain. Energy Technol. Assessments, vol. 45, 2021, doi: 10.1016/j.seta.2021.101074.

[15] H. A. Bogale, A. F. Amhare, and A. A. Bogale, "Assessment of factors affecting vaccine cold chain management practice in public health institutions in east Gojam zone of Amhara region," BMC Public Health, vol. 19, no. 1, 2019, doi: 10.1186/s12889-019-7786-x.

[16] S. A. H. Ahmad, M. N. Ab Rahman, and A. A. Muhamed, "Optimal temperature in cold storage for perishable foods," 2020. 